\title{
Plastic ingestion by mesopelagic fishes in the North Pacific Subtropical Gyre
}

\author{
Peter Davison*, Rebecca G. Asch \\ Scripps Institution of Oceanography at University of California San Diego, La Jolla, California 92093-0208, USA
}

\begin{abstract}
The oceanic convergence zone in the North Pacific Subtropical Gyre acts to accumulate floating marine debris, including plastic fragments of various sizes. Little is known about the ecological consequences of pelagic plastic accumulation. During the 2009 Scripps Environmental Accumulation of Plastics Expedition (SEAPLEX), we investigated whether mesopelagic fishes ingest plastic debris. A total of 141 fishes from 27 species were dissected to examine whether their stomach contents contained plastic particles. The incidence of plastic in fish stomachs was $9.2 \%$. Net feeding bias was evaluated and judged to be minimal for our methods. The ingestion rate of plastic debris by mesopelagic fishes in the North Pacific is estimated to be from 12000 to 24000 tons $\mathrm{yr}^{-1}$. Similar rates of plastic ingestion by mesopelagic fishes may occur in other subtropical gyres.
\end{abstract}

KEY WORDS: Marine debris · Plastic $\cdot$ Mesopelagic fishes $\cdot$ Ingestion $\cdot$ North Pacific Subtropical Gyre $\cdot$ Myctophidae

Resale or republication not permitted without written consent of the publisher

\section{INTRODUCTION}

In contrast to the wide array of studies documenting plastic ingestion by seabirds, sea turtles, and marine mammals, much less is known about the consumption of plastic debris by marine fishes (Hoss \& Settle 1990, Derraik 2002, Boerger et al. 2010). Fishes have been observed to consume plastic in the laboratory, during capture, and in the wild (Lancraft \& Robison 1980, Hoss \& Settle 1990). Small fragments of plastic are of similar size to zooplankton and are potentially consumed by zooplanktivorous fishes. Ingestion of plastic by fishes is of interest as a potential source of their mortality. It may also lead to sublethal effects on growth and reproduction and serve as a point of entry of plastic-associated toxins into the food chain. Hydrophobic toxins have been shown to adsorb to the surface of plastic debris in the ocean (Mato et al. 2001). Other toxins are present as plasticizers, additives, or degradation products in the plastic (Mato et al. 2001, Teuten et al. 2009). Many commercially harvested fish species feed at a high trophic level and may be subject to biomagnification of the toxins ingested by their prey (Arnot \& Gobas 2006).
The North Pacific Subtropical Gyre has one of the highest measured open-ocean concentrations of plastic debris (Moore et al. 2001). Many mesopelagic fishes vertically migrate to the ocean surface at night to feed (Longhurst 1976, Gjosaeter \& Kawaguchi 1980), and are thus collocated with floating plastic when feeding. The fish biomass in subtropical gyres is dominated by these small mesopelagic fishes (Clarke 1980, Mann 1984). The biomass of mesopelagic fishes is immense, and has been estimated at 58 million tons in the North Pacific Subtropical Gyre (Gjosaeter \& Kawaguchi 1980). These fishes are predominantly zooplanktivorous (Clarke 1980, Gartner et al. 1997) and are consumed by squid, piscivorous fishes, seabirds, and marine mammals (Beamish et al. 1999). We hypothesize that mesopelagic fishes inhabiting the North Pacific Subtropical Gyre ingest plastic debris and that plastic enters the marine food web through this pathway.

A problem that has inhibited the ability of scientists to accurately evaluate the extent of plastic ingestion by fishes is the fact that the nets used to capture fishes simultaneously act to catch and concentrate marine debris. The term 'net feeding' refers to the ingestion by 
fishes of organisms or debris that are concentrated in the end of a net while deployed. Net feeding can bias studies of fish diet by altering the composition of prey items and leading to overestimation of ingestion rates. Previous studies of plastic ingestion by fishes have not taken into account this potential source of bias (Carpenter et al. 1972, Boerger et al. 2010). Our study examines the effect of net feeding on the apparent rate of plastic ingestion by deploying multiple types of nets that capture different concentrations of plastic debris and by conducting an experiment to directly measure the incidence of net feeding. To the best of our knowledge, this is the first study of plastic ingestion by fishes that assesses the effect of net feeding, although net feeding itself has been studied by others.

\section{MATERIALS AND METHODS}

Mesopelagic fishes were collected using a variety of methods in August 2009 during the Scripps Environmental Accumulation of Plastics Expedition (SEAPLEX). This cruise sailed between the California Current and the North Pacific Subtropical Gyre aboard the RV 'New Horizon'. Sixteen midwater trawls were performed at 4 stations with a $5 \mathrm{~m}^{2}$ Matsuda-Oozeki$\mathrm{Hu}$ Trawl (MOHT) that had a uniform $1.7 \mathrm{~mm}$ mesh (Oozeki et al. 2004). At each station, 3 trawls were made to $\sim 800 \mathrm{~m}$ depth, and 1 trawl was made to $\sim 200 \mathrm{~m}$ depth. The shallow trawls were conducted at night, while the deep trawls took place both day and night. Tow speed was approximately $1.5 \mathrm{~m} \mathrm{~s}^{-1}$. Tow duration of MOHT casts was approximately 1 and $2 \mathrm{~h}$, for shallow and deep tows, respectively. Trawl locations are shown in Fig. 1. Fishes were also taken with paired $0.71 \mathrm{~m}$ diameter bongo nets (McGowan \& Brown 1966), $0.20 \mathrm{~m}^{2}$ Manta nets (Brown \& Cheng 1981), and dipnets. The depth of bongo tows was $210 \mathrm{~m}$, as estimated by wire angle and wire out. Manta and dipnets sampled the water surface. The tow speed of both Manta and bongo nets was $0.5 \mathrm{~m} \mathrm{~s}^{-1}$. Manta and bongo tow durations were approximately 15 and $22 \mathrm{~min}$, respectively. The mesh size of bongo and Manta nets was 202 and $303 \mu \mathrm{m}$, respectively. Samples were preserved in a solution of $5 \%$ formalin in seawater, $90 \%$ ethanol, or by freezing until they could be processed ashore. Samples preserved in formalin were transferred to $50 \%$ isopropyl alcohol before dissection.

In the laboratory, stomachs of the fishes were removed. The stomachs were then opened, and the contents were rinsed into vials, stained with rose bengal, and then filtered through fiberglass $0.7 \mu \mathrm{m}$ Whatman GF/F filters. The rose bengal stain dyed most forms of organic matter pink, while leaving plastic debris, calcium carbonate, and chitinous material

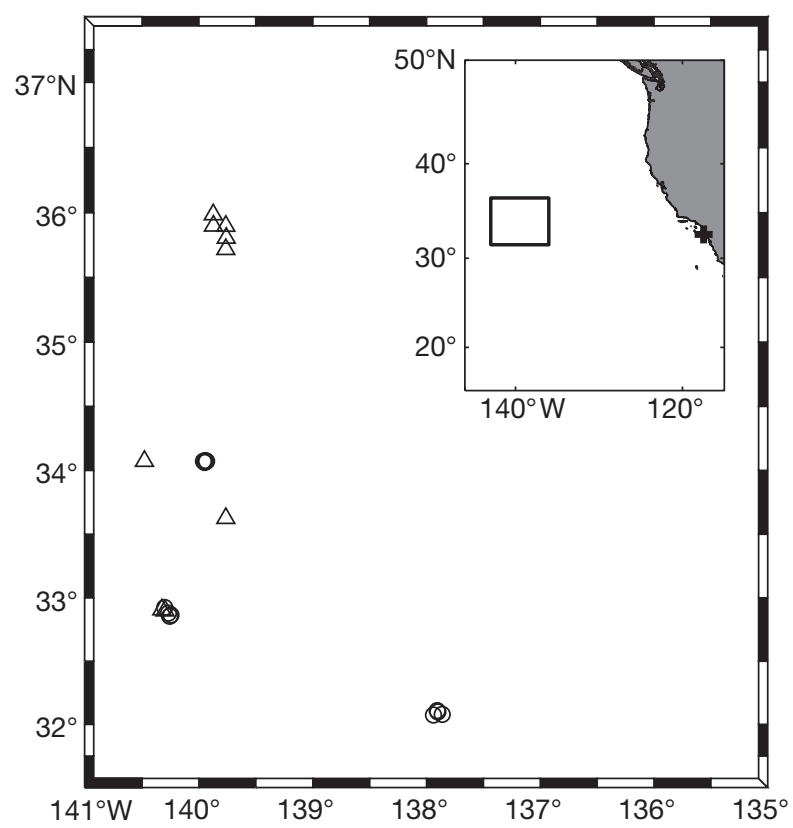

Fig. 1. Locations of the Matsuda-Oozeki-Hu trawls during the Scripps Environmental Accumulation of Plastics Expedition (SEAPLEX) (O), SEAPLEX Manta and bongo tow locations $(\triangle)$, and the net feeding experiment $(\$$, inset). The rectangular box in the inset corresponds to the boundaries of the outer figure

unaffected (Williams \& Williams 1974). The filters were visually inspected under a dissecting microscope for plastic particles. Plastic fragments were mounted on a slide and photographed under $12 \times$ to $50 \times$ magnification with a dissecting microscope. The area of plastic fragments in the photographs was measured with NIH ImageJ software. The depth of plastic fragments was estimated with the ocular micrometer of a dissecting microscope. Only plastic fragments were considered for volume calculations, as it was difficult to estimate the volume of plastic films and fibers that were found in our samples.

In addition to the comparatively large fibers included in the classification above, small-diameter and brightly colored fibers were observed in the filtered stomach contents of many fishes. These particles were similar to micro-plastic from coastal sediment described by Thompson et al. (2004), which were subsequently observed to be consumed by small invertebrates. These small-diameter fibers were not counted as plastic particles since similar fibers were also observed in empty Petri dishes, and we could not eliminate the possibility of contamination. Future investigations of the consumption of micro-plastic by fishes should take precautions against contamination by airborne fibers.

The ability of our methods to detect plastic was tested using spherical plastic beads of 2 size ranges 
( 0.71 to 0.85 and 1.41 to $1.68 \mathrm{~mm}$ in diameter). A random number of beads ( 0 to 3 ) from each size class was mixed into the stomach contents of 10 myctophid fishes and processed as above. Examination of stomach contents for plastic beads was done blindly, such that the researcher performing this task did not know how many beads were in each stomach. Of the 10 trials performed to assess the detection of plastic beads of known diameter, we were able to correctly identify the size class and number of all plastic beads present in fish stomachs. However, there was 1 false positive, in which a bead from the smaller size class was 'identified' from a sample containing no beads. The results of this experiment indicated that we were able to accurately detect plastic particles $>1 \mathrm{~mm}$ in diameter.

In a separate experiment designed to evaluate the prevalence of net feeding, $473 \mathrm{ml}$ of chopped up rubber bands were placed in the cod end of an $8 \mathrm{~m}^{2}$ IsaacsKidd midwater trawl (Isaacs \& Kidd 1953) before deployment in the San Diego trough on a $1 \mathrm{~d}$ cruise of the RV 'New Horizon'. The rubber bands were composed of equal volumes from 2 size classes: $2 \times 3 \times 1$ and $4 \times 4$ $\times 1 \mathrm{~mm}$. The Isaacs-Kidd midwater trawl had a uniform $6 \mathrm{~mm}$ square mesh net liner, and the last $2 \mathrm{~m}$ of the net before the cod end was composed of $303 \mu \mathrm{m}$ plankton mesh. The cod end was a plastic cylinder with vents covered by $1.7 \mathrm{~mm}$ mesh. Fishes from the trawl were preserved in a solution of $5 \%$ formalin in seawater and then transferred to $50 \%$ isopropyl alcohol before dissection. The buccal cavity of each fish was inspected under a dissecting microscope for the presence of rubber bands before removal of the stomachs. Stomachs were then opened and inspected for rubber bands.

\section{RESULTS}

\section{Plastic ingestion by fishes}

A total of 141 fishes from 27 species and 4 families were dissected (Table 1). Plastic items were found inside the stomachs of 13 fishes, $9.2 \%$ of the fishes sampled. We found plastic in the stomachs of $4.8 \%$ of mesopelagic fishes from non-vertically migratory taxa (e.g. Gonostomatidae, Sternoptychidae, Stomiidae, Nannobrachium regale, and Taaningichthys bathyphilus) and of $11.6 \%$ of migratory taxa (e.g. other Myctophidae). The lower incidence of plastic in nonmigratory fishes may reflect a decreased concentration of plastic at depths where feeding occurs. This ingestion estimate is conservative because plastic may have been present in intestines (which were not dissected), lost during stomach eversion, missed during visual inspection of stomach contents, and because some small-diameter fibers could not be verified as marine
Table 1. Fish species dissected following the Scripps Environmental Accumulation of Plastics Expedition (SEAPLEX)

\begin{tabular}{|c|c|c|}
\hline Species & $\begin{array}{l}\text { No. of fish } \\
\text { dissected }\end{array}$ & $\begin{array}{l}\text { No. of fish } \\
\text { with plastic }\end{array}$ \\
\hline \multicolumn{3}{|l|}{ Gonostomatidae } \\
\hline Cyclothone acclinidens & 4 & 0 \\
\hline Cyclothone atraria & 3 & 0 \\
\hline Cyclothone pallida & 5 & 0 \\
\hline Cyclothone pseudopallida & 4 & 0 \\
\hline \multicolumn{3}{|l|}{ Sternoptychidae } \\
\hline Argyropelecus affinis & 1 & 0 \\
\hline Argyropelecus hemigymnus & 3 & 0 \\
\hline Danaphos oculatus & 9 & 0 \\
\hline Sternoptyx diaphana & 4 & 1 \\
\hline Sternoptyx pseudobscura & 6 & 1 \\
\hline \multicolumn{3}{|l|}{ Stomiidae } \\
\hline Idiacanthus antrostomus & 4 & 1 \\
\hline \multicolumn{3}{|l|}{ Myctophidae } \\
\hline Bolinichthys longipes & 3 & 0 \\
\hline Ceratoscopelus warmingii & 8 & 0 \\
\hline Diaphus anderseni & 13 & 2 \\
\hline Diaphus fulgens & 7 & 2 \\
\hline Diaphus phillipsi & 1 & 1 \\
\hline Diogenichthys atlanticus & 5 & 0 \\
\hline Hygophum proximum & 2 & 0 \\
\hline Hygophum reinhardtii & 2 & 0 \\
\hline Lampadena urophaos & 1 & 0 \\
\hline Lobianchia gemellarii & 3 & 1 \\
\hline Myctophum nitidulum & 25 & 4 \\
\hline Nannobrachium fernae & 1 & 0 \\
\hline Nannobrachium hawaiiensis & 17 & 0 \\
\hline Nannobrachium regale & 1 & 0 \\
\hline Notolychnus valdiviae & 3 & 0 \\
\hline Notoscopelus resplendens & 3 & 0 \\
\hline Taaningichthys bathyphilus & 3 & 0 \\
\hline Total & 141 & 13 \\
\hline
\end{tabular}

debris. Eleven of the fishes that ingested plastic had only a single piece of plastic in their stomach, while 2 individuals had ingested 2 pieces. The plastic recovered from fish stomachs could be categorized as small fragments $(57 \%)$, fibers $(36 \%)$, or clear films $(7 \%)$. Yellowish-white, blue, green, black, and transparent plastic were recovered from stomachs (Fig. 2). The mean length of the longest dimension of plastic fragments was $2.2 \mathrm{~mm}$ (1.9 mm SD), with some plastic fibers much longer. The mean volume of plastic fragments was $3.5 \mathrm{~mm}^{3}$ (5.4 $\left.\mathrm{mm}^{3} \mathrm{SD}\right)$. Volume was not estimated for ingested plastic films or fibers. Assuming a density of $0.91 \mathrm{~g} \mathrm{ml}^{-1}$ (Moret-Ferguson et al. 2010), the mean mass of a plastic fragment was $3.1 \mathrm{mg}$.

\section{Net feeding}

Four types of nets were deployed in the convergence zone in the eastern North Pacific Subtropical Gyre to 

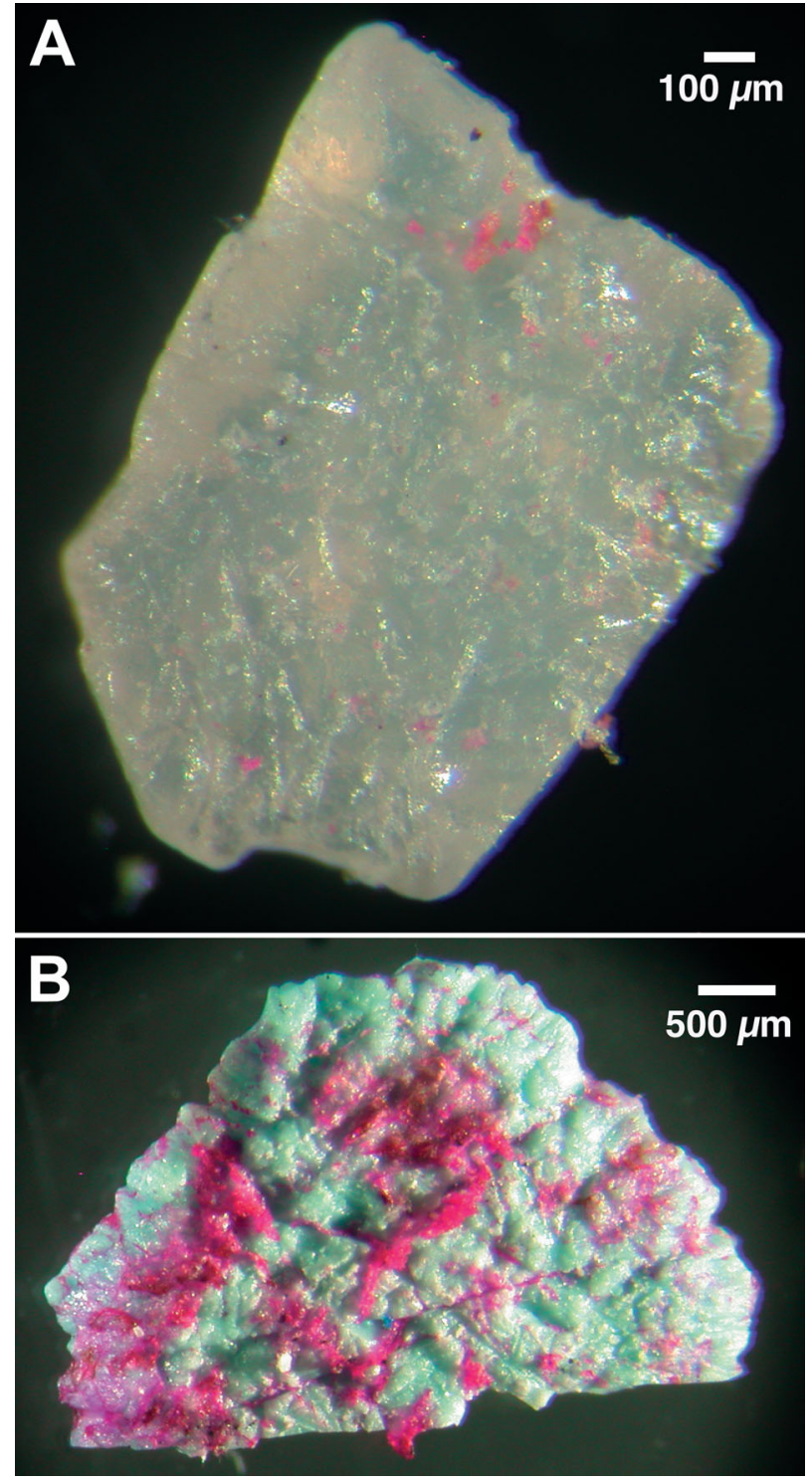

Fig. 2. (A) White plastic particle (longest dimension of $1.5 \mathrm{~mm}$ ) recovered from the stomach of a Myctophum nitidulum. (B) Blue-green plastic particle (longest dimension of $4.4 \mathrm{~mm}$ ) recovered from the stomach of a Sternoptyx pseudobscura.

Pink areas are organic material stained with rose bengal

capture fishes and plastic debris. The quantity of plastic debris captured by the 4 types of nets was visually compared. The greatest concentration of plastic particles was observed with the Manta net, which has a small mesh size and was towed at the sea surface. Oblique epipelagic tows with bongo nets collected much less plastic than was captured in the Manta net, even though the mesh size was fine enough to retain small fragments. Very little plastic was retained in the midwater trawl, which has a large mesh size, a deep tow profile, and was deployed off the stern in the wake of the vessel. No plastic was retained in dipnets used to individually capture neustonic fishes. If net feeding was responsible for a substantial amount of plastic ingestion, we would anticipate a greater incidence of plastic ingestion by fishes in the nets that retained a higher concentration of plastic particles. Instead, the frequency of ingested plastic was similar between fishes collected with the Manta and those captured by other nets (15 and $8 \%$, respectively). This difference was not significant (' $N-1$ ' chi-square test, $\chi^{2}=0.92$, $\mathrm{df}=1, \mathrm{p}=0.34$; Campbell 2007). Note that the only species of mesopelagic fish captured in the Manta net was Myctophum nitidulum (20 individuals).

An experiment was conducted in the California Current to evaluate the bias due to net feeding, in which the cod end of a midwater trawl was seeded with rubber band fragments of 2 size classes before deployment. Most rubber band fragments were retained by the cod end over the course of the trawl. Of 71 fishes dissected from the catch, 4 contained rubber band fragments in their buccal cavity, and only 1 fish was found to have rubber band fragments in its stomach (Table 2). All rubber band fragments recovered from fishes were of the smaller size class, with the exception of 1 large fragment recovered from the stomach of a giant lampfish Parvilux ingens. Of the dissected fishes,

Table 2. Fish species dissected from the California Current during the net feeding experiment. The 'Fish with rubber bands' column is ordered buccal cavity-stomach

\begin{tabular}{|c|c|c|}
\hline Species & $\begin{array}{c}\text { No. of fish } \\
\text { dissected }\end{array}$ & $\begin{array}{l}\text { Fish with } \\
\text { rubber bands }\end{array}$ \\
\hline \multicolumn{3}{|l|}{ Bathylagidae } \\
\hline Bathylagoides wesethi & 9 & $0-0$ \\
\hline \multicolumn{3}{|l|}{ Gonostomatidae } \\
\hline Cyclothone acclinidens & 13 & $1-0$ \\
\hline \multicolumn{3}{|l|}{ Sternoptychidae } \\
\hline Argyropelecus affinis & 1 & $0-0$ \\
\hline Argyropelecus sladeni & 2 & $0-0$ \\
\hline \multicolumn{3}{|l|}{ Stomiidae } \\
\hline Idiacanthus antrostomus & 1 & $0-0$ \\
\hline \multicolumn{3}{|l|}{ Myctophidae } \\
\hline Nannobrachium regale & 2 & $0-0$ \\
\hline Nannobrachium ritteri & 6 & $0-0$ \\
\hline Parvilux ingens & 2 & $1-1^{\mathrm{a}}$ \\
\hline Stenobrachius leucopsarus & 3 & $1-0$ \\
\hline Symbolophorus californiensis & 4 & $1-0$ \\
\hline Triphoturus mexicanus & 24 & $0-0$ \\
\hline \multicolumn{3}{|l|}{ Melamphaeidae } \\
\hline Scopelogadus mizolepis & 3 & $0-0$ \\
\hline \multicolumn{3}{|l|}{ Scorpaenidae } \\
\hline Sebastolobus altivelis & 1 & $0-0$ \\
\hline Total & 71 & $4-1$ \\
\hline
\end{tabular}




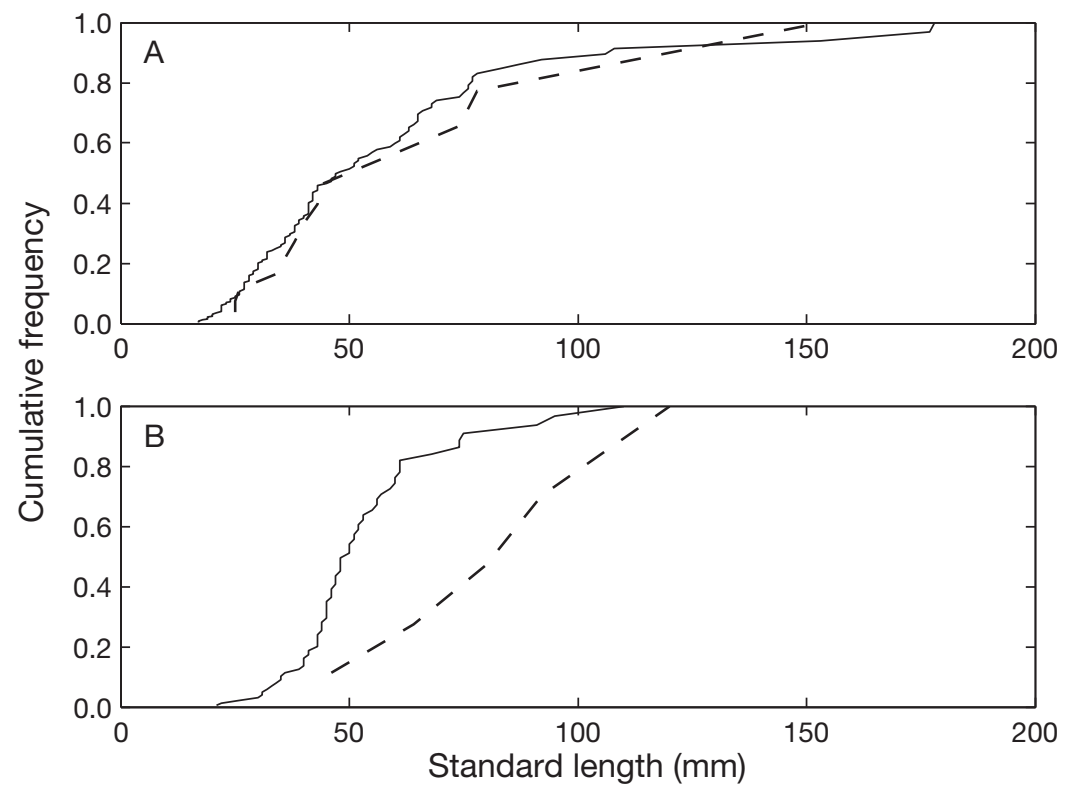

Fig. 3. Empirical cumulative distribution functions of the standard length of fishes containing no plastic (solid line) and fishes that ingested plastic debris (dashed line). (A) Data from the North Pacific Subtropical Gyre collected during the Scripps Environmental Accumulation of Plastics Expedition. (B) Data from the net feeding experiment conducted in the California Current. For comparison purposes, 'ingested' plastic includes that found in a fish's buccal cavity (presumed to be a precondition of net feeding). This looser definition of net feeding was used because only 1 fish swallowed rubber band fragments

$1.4 \%$ had engaged in net feeding, as defined by having plastic in their stomach. In the net feeding experiment, the standard length of fishes containing rubber band fragments (in either their stomach or buccal cavity) was significantly longer than fishes that did not contain them $(\mathrm{p}=0.01$, Kolmogorov-Smirnov statistic $=$ 0.69; Fig. 3). In contrast, the standard lengths of fish that did and did not ingest plastic during SEAPLEX were not significantly different from each other $(\mathrm{p}=$ 0.72, Kolmogorov-Smirnov statistic $=0.19$; Fig. 3).

\section{DISCUSSION}

\section{Net feeding}

Previous investigations of net feeding on artificial items by mesopelagic fishes have produced results that indicate higher levels of net feeding than our experiment. Robison (1984) found net feeding rates of 10 to $50 \%$ for 4 species. Three of these species (Argyropelecus affinis, Ceratoscopelus warmingii, and Lobianchia gemellarii) were common to our samples from the North Pacific Subtropical Gyre. Lancraft \& Robison (1980) estimated a $4.9 \%$ incidence of net feeding amongst mesopelagic fishes, in comparison with our result of $1.4 \%$ from the same ecosystem. Our results are similar to those of Lancraft \& Robison (1980) in that both experiments indicated an increased incidence of net feeding amongst larger fishes. Differences in the size spectra of fishes that did and did not ingest rubber band fragments (Fig. 3) during the net feeding experiment indicate that larger fishes are less likely to reject non-food items of the experimental size. This conclusion is supported by the observation that all but one of the recovered rubber band fragments was from the smaller size class. Lancraft \& Robison (1980) hypothesized that this finding may be due to the fact that larger fishes survive for longer after capture, allowing them to engage in more net feeding.

Two lines of evidence suggest that the plastic ingestion by fishes in the present study cannot be attributed to net feeding. First, the 4 types of nets used during SEAPLEX differed in their capture or retention of plastic debris. If our results were strongly affected by net feeding, we would expect the highest incidence of plastic ingestion in fishes captured with the Manta net, which retained the most plastic debris. Instead, the percentage of fishes that had ingested plastic did not significantly differ amongst nets. A related line of evidence suggesting that our observed rate of plastic ingestion is not a net feeding artifact is that one of the fishes containing plastic was captured in a dipnet. Due to the fact that essentially no plastic was retained in dipnets, this fish almost certainly ingested the plastic fragment before capture.

Second, the percentage of fishes from SEAPLEX that ingested plastic was 6.6 times larger than the percentage that ingested rubber band fragments in our net feeding experiment, even though the concentration of rubber bands in the cod end was much greater than plastic concentrations observed in SEAPLEX. The 2 results were statistically different (' $\mathrm{N}-1$ ' chi-square test for contingency table, $\chi^{2}=4.47$, df $=1, p=0.03$; Campbell 2007).

\section{Plastic ingestion by fishes}

To the best of our knowledge, there have been only 4 previous studies that specifically investigated plastic ingestion by fishes in marine environments containing a high concentration of plastic micro-debris (Carpenter 
et al. 1972, Colton et al. 1974, Kartar et al. 1976, Boerger et al. 2010). Three of these studies differed from ours because they exclusively focused on larval and juvenile fishes in coastal and epipelagic habitats, while our research examined adult, mesopelagic fishes. Nevertheless, our results are similar to most of these studies in terms of the percentage of fishes ingesting plastic ( 0 to $11 \%$ ). Carpenter et al. (1972) observed that 8 of 14 fish species collected off the northeastern United States contained white, plastic spherules in their guts. Their study found that the overall incidence of plastic ingestion was $5.2 \%$. Similarly, a study in an English estuary with a high concentration of polystyrene particles reported that $10.5 \%$ of the fishes had ingested plastic (Kartar et al. 1976). A third study found no plastic particles in the guts of $>500$ larval and juvenile fishes collected from an area of the northwestern Atlantic that contained a high concentration of floating plastic debris (Colton et al. 1974).

In contrast, our results differed from those of Boerger et al. (2010), whose research also investigated plastic ingestion by mesopelagic fishes in the North Pacific Subtropical Gyre. These authors reported a $35 \%$ incidence of plastic in fish stomachs, with a mean of 2.1 pieces of plastic per fish. This percentage is 3.3 times greater than the next highest rate of plastic ingestion reported from fishes in the wild. The discrepancy between our findings and those of Boerger et al. (2010) may be attributable to the influence of net feeding. The Manta net used by Boerger et al. (2010) to capture mesopelagic fishes was deployed for 1.5 to $5.5 \mathrm{~h}$ at a time. This unusually long tow duration implies that the collected fishes may have been in contact for hours with elevated and increasing concentrations of plastic in the cod end of the net. Long tow durations have a higher risk of net feeding bias than shorter tows. Further evidence of net feeding is suggested by the fact that Boerger et al. (2010) observed a greater concentration of plastic debris in the stomachs of larger fishes. Our results, as well as those of Lancraft \& Robison (1980), indicate that a higher incidence of net feeding occurs among larger fishes. In contrast, our findings suggest that ingestion of plastic in the wild is independent of the size of a fish.

In addition to these studies, which focused specifically on plastic ingestion, other research examining the diet of fishes has incidentally noted the occurrence of man-made debris in gut contents. For example, plastic has been recovered from the stomachs of tuna (Manooch \& Mason 1983). Plastic cups have been found in the stomachs of fishes in the English Channel (Anonymous 1975). Plastic debris was observed in the stomachs of $14 \%$ of the southern opah Lampris immaculatus collected on the Patagonian Shelf (Jackson et al. 2000). There has been 1 indirect observation of plastic consumption by mesopelagic fishes in the wild (Eriksson \& Burton 2003).

The implications of plastic ingestion on the health and survival of mesopelagic fishes remain uncertain and is an area where further study is needed. Few ill effects have been directly observed to date in pelagic fishes. Hoss \& Settle (1990) found that plastic spheres fed to larval and juvenile fishes in a laboratory setting did not cause intestinal blockage, prevent fishes from defecating, or increase mortality. Mesopelagic fishes have been found to contain hydrophobic toxins, but it is unclear whether these concentrations are in equilibrium with the ambient water or biomagnify from the ingestion of contaminated prey (Baird et al. 1975, Harding et al. 1997, Takahashi et al. 2000). The toxic load of a fish in equilibrium with the ambient water would not increase through the consumption of plastic debris. It has not yet been shown that ingestion of plastic debris by mesopelagic fishes leads to biomagnification of plastic-associated toxins in higher trophic levels.

A rough estimate of the rate of plastic ingestion by mesopelagic fishes in the North Pacific Subtropical Gyre is possible. This estimate is made to assess the potential scale and importance of plastic ingestion by mesopelagic fishes. More rigorous estimates would require data from a wider geographic area. Ingested plastic fibers and films are assumed to have zero volume for this calculation. Of mesopelagic fishes, 9.2\% contained plastic debris in their stomach, although plastic fragments were found in only $4.8 \%$ of mesopelagic fishes. When these percentages are scaled by the area of the gyre $\left(3.8 \times 10^{7} \mathrm{~km}^{2}\right.$; Gjosaeter \& Kawaguchi 1980), the biomass of mesopelagic fishes (1 to $2 \mathrm{~g} \mathrm{~m}^{-2}$; Gjosaeter \& Kawaguchi 1980), the mean weight of a mesopelagic fish (0.5 g; Maynard et al. 1975), and the mean mass of ingested plastic fragments ( $3.1 \mathrm{mg})$, it can be estimated that 3.5 to 7.1 million tons of mesopelagic fishes contain 12000 to 24000 tons of plastic in the North Pacific Subtropical Gyre. Most tropical and subtropical mesopelagic fishes have an annual lifespan (Clarke 1973, Gjosaeter \& Kawaguchi 1980), and mesopelagic fish biomass in the North Pacific Subtropical Gyre does not vary seasonally (Barnett 1975). Therefore, the mass of plastic that was found in mesopelagic fishes is representative of the annual consumption of plastic, if consumption of plastic does not increase mortality and no plastic is regurgitated or passed (all conservative assumptions). It should also be noted that the biomass estimate used here is conservative, as nets are subject to significant avoidance and escapement biases (Koslow et al. 1997).

In conclusion, $9.2 \%$ of mesopelagic fishes residing in the North Pacific Subtropical Gyre were found to contain plastic debris. Some of the plastic was ingested by 
non-migratory fishes at thermocline depths, indicating a potential subsurface concentration of suspended debris. Net feeding bias was minimal; mesopelagic fishes consumed plastic debris prior to capture. The observed frequency of plastic ingestion is consistent with the consumption of 10 s of thousands of tons of plastic annually by mesopelagic fishes in the North Pacific Subtropical Gyre. Similar rates of plastic ingestion by fishes may occur in other subtropical gyres, where the convergence of currents leads to the accumulation of plastic debris.

Acknowledgements. P.D. was supported by a NASA Earth and Space Science Fellowship, and R.G.A. was funded through a NOAA Nancy Foster Scholarship. Funding for the SEAPLEX cruise was provided by University of California Ship Funds, Project Kaisei/Ocean Voyages Institute, and NSF IGERT Grant No. 0333444. Wire time for a midwater trawl was provided by L. Levin (SIO 277). The authors thank the captain, crew, and science party of the RV 'New Horizon' for assistance in deployment of the midwater trawls and processing the catch. Fishes were contributed by M. Goldstein and J. Powell. N. Pincus assisted in the laboratory. C. Klepadlo from the Scripps Institution of Oceanography Marine Vertebrate Collection helped with the identification of mesopelagic fishes. Chemicals, equipment, and laboratory space were provided by the SIO Marine Vertebrate and Pelagic Invertebrate Collections, D. Checkley, and J. Koslow. Conversations with M. Goldstein and D. Checkley helped refine our methods and improve this manuscript.

\section{LITERATURE CITED}

Anonymous (1975) Plastic cups found in fish. Mar Pollut Bull 6:148

Arnot JA, Gobas F (2006) A review of bioconcentration factor (BCF) and bioaccumulation factor (BAF) assessments for organic chemicals in aquatic organisms. Environ Rev 14: 257-297

Baird RC, Thompson NP, Hopkins TL, Weiss WR (1975) Chlorinated hydrocarbons in mesopelagic fishes of the eastern Gulf of Mexico. Bull Mar Sci 25:473-481

Barnett M (1975) Studies on the patterns of distribution of mesopelagic fish faunal assemblages in the central Pacific and their temporal persistence in the gyres. $\mathrm{PhD}$ thesis, University of California San Diego, La Jolla, CA

Beamish RJ, Leask KD, Ivanov OA, Balanov AA, Orlov AM, Sinclair B (1999) The ecology, distribution, and abundance of midwater fishes of the Subarctic Pacific gyres. Prog Oceanogr 43:399-442

Boerger CM, Lattin GL, Moore SL, Moore CJ (2010) Plastic ingestion by planktivorous fishes in the North Pacific Central Gyre. Mar Pollut Bull 60:2275-2278

Brown DM, Cheng L (1981) New net for sampling the ocean surface. Mar Ecol Prog Ser 5:225-227

Campbell I (2007) Chi-squared and Fisher-Irwin tests of twoby-two tables with small sample recommendations. Stat Med 26:3661-3675

Carpenter EJ, Anderson SJ, Harvey GR, Miklas HP, Peck BB (1972) Polystyrene spherules in coastal waters. Science 178:749-750

Clarke TA (1973) Some aspects of the ecology of lanternfishes
(Myctophidae) in the Pacific Ocean near Hawaii. Fish Bull 71:401-434

Clarke TA (1980) Diets of 14 species of vertically migrating mesopelagic fishes in Hawaiian waters. Fish Bull 78: 619-640

Colton JB, Knapp FD, Burns BR (1974) Plastic particles in surface waters of the northwestern Atlantic. Science 185: 491-497

> Derraik JGB (2002) The pollution of the marine environment by plastic debris: a review. Mar Pollut Bull 44:842-852

> Eriksson C, Burton H (2003) Origins and biological accumulation of small plastic particles in fur seals from Macquarie Island. Ambio 32:380-384

Gartner JV, Crabtree RE, Sulak KJ (1997) Feeding at depth. In: Randall DJ, Farrell AP (eds) Deep-sea fishes, Book 16. Academic Press, San Diego, CA, p 115-193

Gjosaeter J, Kawaguchi K (1980) A review of the world resources of mesopelagic fish. FAO Fish Tech Pap 193: $1-151$

Harding GC, LeBlanc RJ, Vass WP, Addison RF and others (1997) Bioaccumulation of polychlorinated biphenyls (PCBs) in the marine pelagic food web, based on a seasonal study in the southern Gulf of St. Lawrence, 1976-1977. Mar Chem 56:145-179

Hoss DE, Settle LR (1990) Ingestion of plastics by teleost fishes. In: Shomura RS, Godfrey ML (eds) Proceedings of the second international conference on marine debris. US Department of Commerce, NOAA Technical Memo, Honolulu, HI, p 693-709

Isaacs JD, Kidd LW (1953) Isaacs-Kidd midwater trawl final report. SIO Oceanogr Equip Rep 1:1-21

> Jackson GD, Buxton NG, George MJA (2000) Diet of the southern opah Lampris immaculatus on the Patagonian Shelf; the significance of the squid Moroteuthis ingens and anthropogenic plastic. Mar Ecol Prog Ser 206:261-271

> Kartar S, Abou-Seedo F, Sainsbury M (1976) Polystyrene spherules in the Severn Estuary-a progress report. Mar Pollut Bull 7:52

> Koslow JA, Kloser RJ, Williams A (1997) Pelagic biomass and community structure over the mid-continental slope off southeastern Australia based upon acoustic and midwater trawl sampling. Mar Ecol Prog Ser 146:21-35

Lancraft TM, Robison BH (1980) Evidence of postcapture ingestion by midwater fishes in trawl nets. Fish Bull 77: 713-715

Longhurst AR (1976) Vertical migration. In: Cushing DH (ed) The ecology of the sea. Blackwell, Oxford, p 116-137

Mann KH (1984) Fish production in open ocean ecosystems. In: Fasham MJR (ed) Flows of energy and materials in marine ecosystems. Plenum Press, New York, NY, p 435-458

Manooch CSI, Mason DL (1983) Comparative food studies of yellowfin tuna, Thunnus albacares, and blackfin tuna, Thunnus atlanticus (Pisces: Scombridae), from the southeastern and gulf coast of the United States. Acta Ichthyol Piscat 8:25-46

Mato Y, Isobe T, Takada H, Kanehiro H, Ohtake C, Kaminuma T (2001) Plastic resin pellets as a transport medium for toxic chemicals in the marine environment. Environ Sci Technol 35:318-324

Maynard SD, Riggs FV, Walters JF (1975) Mesopelagic micronekton in Hawaiian waters-faunal composition, standing stock, and diel vertical migration. Fish Bull 73: 726-736

McGowan JA, Brown DM (1966) A new opening-closed paired zooplankton net. Bull Scripps Inst Oceanogr Univ Calif 66(23):1-56

Moore CJ, Moore SL, Leecaster MK, Weisberg SB (2001) A 
comparison of plastic and plankton in the North Pacific Central Gyre. Mar Pollut Bull 42:1297-1300

Moret-Ferguson S, Law KL, Proskurowski G, Murphy EK, Peacock EE, Reddy CM (2010) The size, mass, and composition of plastic debris in the western North Atlantic Ocean. Mar Pollut Bull 60:1873-1878

> Oozeki Y, Hu FX, Kubota H, Sugisaki H, Kimura R (2004) Newly designed quantitative frame trawl for sampling larval and juvenile pelagic fish. Fish Sci 70:223-232

Robison BH (1984) Herbivory by the myctophid fish Ceratoscopelus warmingii. Mar Biol 84:119-123

Takahashi S, Tanabe S, Kawaguchi K (2000) Organochlorine

Editorial responsibility: Hans Heinrich Janssen,

Oldendorf/Luhe, Germany and butyltin residues in mesopelagic myctophid fishes from the western North Pacific. Environ Sci Technol 34: 5129-5136

- Teuten EL, Saquing JM, Knappe DRU, Barlaz MA and others (2009) Transport and release of chemicals from plastics to the environment and to wildlife. Philos Trans R Soc Lond B 364:2027-2045

Thompson RC, Olsen Y, Mitchell RP, Davis A and others (2004) Lost at sea: Where is all the plastic? Science 304:838

Williams DD, Williams NE (1974) Counterstaining technique for use in sorting benthic samples. Limnol Oceanogr 19: $152-154$

Submitted: December 20, 2010; Accepted: March 21, 2011

Proofs received from author(s): June 7, 2011 